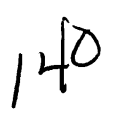

\title{
Death After Transplantation
}

\section{An Analysis of Sixty Cases}

$\mathrm{T}$ ISSUE transplantation has become a widely practiced mode of therapy for chronic disease of a variety of organs. When the transplanted tissue has minimal antigenic capacity, when its antigens are similar to those of the recipient, when viability is not required for success, or when the graft is protected from the host, success in transplantation has been readily achieved for many years. Homotransplants of bone, cornea and portions of vessels are in this category, as are isogeneic grafts in which tissue is simply moved from one site to another in the same person. Identical twins likewise have identical antigens and can readily reciprocate tissues. However, transplantation for replacement of major organs has posed major difficulties.

Some of the technical problems in the transplantation of major organs were worked out a number of years ago when kidney homotransplantation between identical twins was achieved [1]. With a deeper understanding of immunologic mechanisms, and particularly with the discovery of methods for variable attenuation of the immune response [2], it became theoretically possible to control immunologic rejection of transplanted organs. Major achievements in this regard have been reported in animals. Attempts in man have met with varying but encouraging degrees of success [3].

Attempts have been made to transplant a variety of functional organs [4] but substantial success in prolonging useful life through such procedures has been limited to kidney transplantation. In analyzing the data that have become available in the past four years it has become clear that the problem of suppressing the host's immune response has by no means been conquered, and current efforts are aimed at providing closer antigenic matches between donor and recipient [5]. Meanwhile, the most effective treatment continues to be immunosuppression with drugs and radiation.

This communication is an analysis of the causes of death among patients who have received kidney, liver and spleen grafts at the University of Colorado Medical Center and Denver Veterans Administration Hospital. It is suggested that in selected cases a pernicious yet unavoidable chain of events ensue early in the postoperative period, viz., a violent immunologic reaction on the part of the recipient necessitating correspondingly vigorous immunosuppression which so damages the host's defense mechanisms that he is unable to resist infestation by ambient or saprophytic organisms, to which he often succumbs. Patients in whom this chain of events never begins have a relatively favorable prognosis, but when there is an early and continued need for a high level of steroid therapy and immunosuppression, the patient predictably 
TABLE I

MORTALITY IN TRANSPLANT RECIPIENTS (123 PATIENTS)

\begin{tabular}{|c|c|c|c|}
\hline Data & $\begin{array}{l}\text { Patients } \\
\text { (no.) }\end{array}$ & $\begin{array}{l}\text { Deaths } \\
\text { (no.) }\end{array}$ & $\begin{array}{c}\text { Mor- }- \\
\text { tality } \\
(\%)\end{array}$ \\
\hline \multicolumn{4}{|l|}{ Kidney homotransplants } \\
\hline Related live donor & 64 & 23 & 36 \\
\hline Unrelated live donor & 35 & 22 & 63 \\
\hline Cadaver donor & 6 & 4 & 66 \\
\hline Identical twin donor & 2 & 0 & 0 \\
\hline $\begin{array}{l}\text { (kidney homotrans- } \\
\text { plants) }\end{array}$ & 107 & 49 & 46 \\
\hline $\begin{array}{l}\text { Baboon kidney heterotrans- } \\
\text { plants }\end{array}$ & 6 & 6 & 100 \\
\hline Liver transplants & 7 & 7 & 100 \\
\hline $\begin{array}{l}\text { Spleen transplants } \\
\text { Totals }\end{array}$ & 3 & 3 & 100 \\
\hline (all transplants) & 123 & 65 & 53 \\
\hline
\end{tabular}

Note: Data include all fatalities. All subsequent tables include only the sixty patients examined at autopsy at the University of Colorado Medical Center and Denver Veterans Administration Hospital.

will have a protracted and difficult course, although death or graft failure may be delayed for months or years.

From the start of the program in human organ transplantation at this Center in March 1962, through December 1965, 123 patients received organ transplants. The program was separated into two phases by a hiatus of six months (March through September 1964) for evaluation of results. Included are 113 kidney transplants, of which sixty-four were from living related donors, thirty-five from living unrelated donors, six from cadaver donors, six from baboons and two from identical twins. In addition, there were seven liver homotransplants in patients with hepatoma or liver failure due to cirrhosis, and spleen homotransplants in three patients with metastatic carcinoma. As of March 31, 1966, sixty-five patients had died at from zero to 930 days after surgery. Five patients died elsewhere and their data are not included in this report.

Methods of selection of patients, operative details and postoperative care have been published elsewhere [6]. It is worth emphasizing, however, that all had terminal disease and that, with the exception of the grafts in identical twins, adjunctive and postoperative treatment included splenectomy (with the exception of two patients), azathioprine, prednisone, thymectomy in selected cases, and often actinomycin
$\mathrm{C}$ and local radiation of the kidneys. The dose of azathioprine was adjusted in general so that leukocytosis was suppressed and a normal white blood cell count was maintained. Prednisone was used at the dose level required to suppress evidence of immunologic intolerance of the graft, and actinomycin $\mathrm{C}$ and local radiation were employed adjunctively during periods of rejection crisis. Following the moratorium (October 1964), a slightly different therapeutic approach was adopted which included utilization of prospective antigen matching of the donor-recipient pairs [7] and a more conservative use of azathioprine. The two identical twins received no immunosuppressive therapy.

Whenever clinical infection became apparent, antimicrobial agents were administered in most cases according to the type of organism recognized. In some cases brief therapy with methicillin was given at the time of surgery in order to prevent staphylococcal wound infections. Other drugs included, when necessary, potentially nephrotoxic agents such as polymyxin-B and kanamycin.

At autopsy, routine procedures for culture, dissection, and preparation of tissues were employed. Periodic acid-Schiff, methenamine silver, Giemsa, Brown and Brenn, and ZiehlNeelsen stains were employed for the demonstration of microorganisms in tissue sections and occasionally in smears.

The over-all mortality was 53 per cent, but the survival rate in patients receiving grafts from close relatives was approximately twice that in patients who received their grafts from unrelated donors (Table I). The identical twin recipients are both living and well.

In the group of sixty-two patients given trans-

TABLE II

PRIMARY CAUSES OF EARLY DEATH* (SIXTEEN PATIENTS)

\begin{tabular}{lc}
\hline \multicolumn{1}{c}{ Cause of Death } & $\begin{array}{c}\text { Patients } \\
\text { (no.) }\end{array}$ \\
\hline Pulmonary embolism and/or infarct & 5 \\
Sepsis & 4 \\
Renal failure & 2 \\
Myocardial infarct & 1 \\
Congestive heart failure & 1 \\
Electrolyte imbalance & 1 \\
Hemorrhage & 1 \\
Ruptured spleen & 1 \\
$\quad$ Total & 16 \\
\hline
\end{tabular}

* Zero to twenty-four days after surgery.

AMERICAN JOURNAL OF MEDIGINE 
plants prior to March 1964, fourteen deaths occurred during the first twenty-four postoperative days. Early deaths were much less common during the next twenty-five months, only two occurring in sixty-one patients. Causes of early death are listed in Table II. It is apparent that two thirds of these resulted from general postoperative complications and one third were related to immunologic or infectious complications. Considerable improvement in the incidence of postoperative complications is manifest.

By contrast, among the forty-four patients who died twenty-five days or more after surgery, death was clearly related to infection in thirtyeight (86 per cent) (Table III). Multiple infections were common (Table Iv). The organisms responsible for late infections are for the most part opportunistic rather than common pathogens. For instance, infections with grampositive pyogenic organisms (staphylococcus, streptococcus and pneumococcus) were rarely recorded. The virtual absence of this latter group almost certainly reflects their relative ease of identification and their susceptibility to antibiotic therapy. The organisms responsible for fatal infections in these patients are, by and large, difficult to deal with under the best circumstances. Infection with pseudomonas, nocardia and fungi accounted for a substantial majority ( 73 per cent) of deaths.

In contrast to the diminution in the early death rate noted during the second phase, the late death rate (due to sepsis) has not decreased. Among the sixty-two patients who received grafts before February 1964, fourteen of eighteen late deaths (78 per cent) were due to septic complica-

TABLE III

PRIMARy CAUSES OF LATE DEATH* (FORTy-FOUR PATIENTS)

\begin{tabular}{lc}
\hline \multicolumn{1}{c}{ Cause of Death } & $\begin{array}{c}\text { Patients } \\
\text { (no.) }\end{array}$ \\
\hline Sepsis & 38 \\
Renal failure & 5 \\
Hepatitis & 1 \\
Hemorrhage & 1 \\
Pulmonary emboli & 1 \\
Congestive heart failure & 1 \\
Pancreatitis & 1 \\
Unknown & 1 \\
Total & $49 \dagger$ \\
\hline
\end{tabular}

* More than twenty-four days after surgery.

$\dagger$ Five patients were assigned two causes of death.

VOL. 42, MARG H 1967
TABLE IV

ORGANISMS REGOVERED AT AUTOPSY (SIXTY PATIENTS)

\begin{tabular}{lcc}
\hline \multicolumn{1}{c}{ Organism } & $\begin{array}{c}\text { Cause of } \\
\text { Death } \\
\text { (no.) }\end{array}$ & $\begin{array}{c}\text { Ancillary } \\
\text { Infection } \\
\text { (no.) }\end{array}$ \\
\hline Pseudomonas & 15 & 1 \\
Paracolon, Klebsiella, Esch. coli & 7 & 2 \\
Staphylococcus, pneumococcus & 3 & \\
Nocardia & 3 & \\
Aspergillus & 7 & \\
Candida & 9 & 6 \\
Histoplasma & 1 & 1 \\
Pneumocystis & 2 & 7 \\
Hepatitis & 1 & 30 \\
Cytomegalovirus & & 1 \\
Herpes zoster & & 1 \\
Herrellea & & 1 \\
Serratia & & 2 \\
M. tuberculosis & & 1 \\
Sporozoon, unidentified & & 53 \\
$\quad$ Totals & 48 & \\
\hline
\end{tabular}

tions. There have been thirty-one late deaths since then in a population of eighty-nine, which includes survivors from the original series plus patients operated on since then. Five of these died elsewhere; twenty-three of the remainder $(88$ per cent) died of infection. Among this group of eighty-nine subjects fifty-eight are living, thirtythree of whom have survived longer than twentyfour months.

Cytomegalovirus and Pneumocystis carinii were found with extraordinary frequency. Pneumocystis was identified in nine patients, ${ }^{*}$ although in only two of these was pulmonary insufficiency secondary to the parasitic infection believed to be the primary cause of death. Despite the frequency of cytomegalovirus found in the lungs and elsewhere in thirty of the patients in this group (50 per cent), the virus did not appear to be a cause of death in any case. Details of these infections have been published elsewhere $[8,9]$.

Fungal infections were also frequent [10]. The pathogens most commonly found were candida and aspergillus, but histoplasma and nocardia were also seen. Double fungus infections were observed three times and bacterial infection often was present coincidentally.

Comparison of the survival times of patients who died of noninfectious causes with those of patients who died with pseudomonas, fungus

* A tenth case was reportedly found at autopsy elsewhere. 


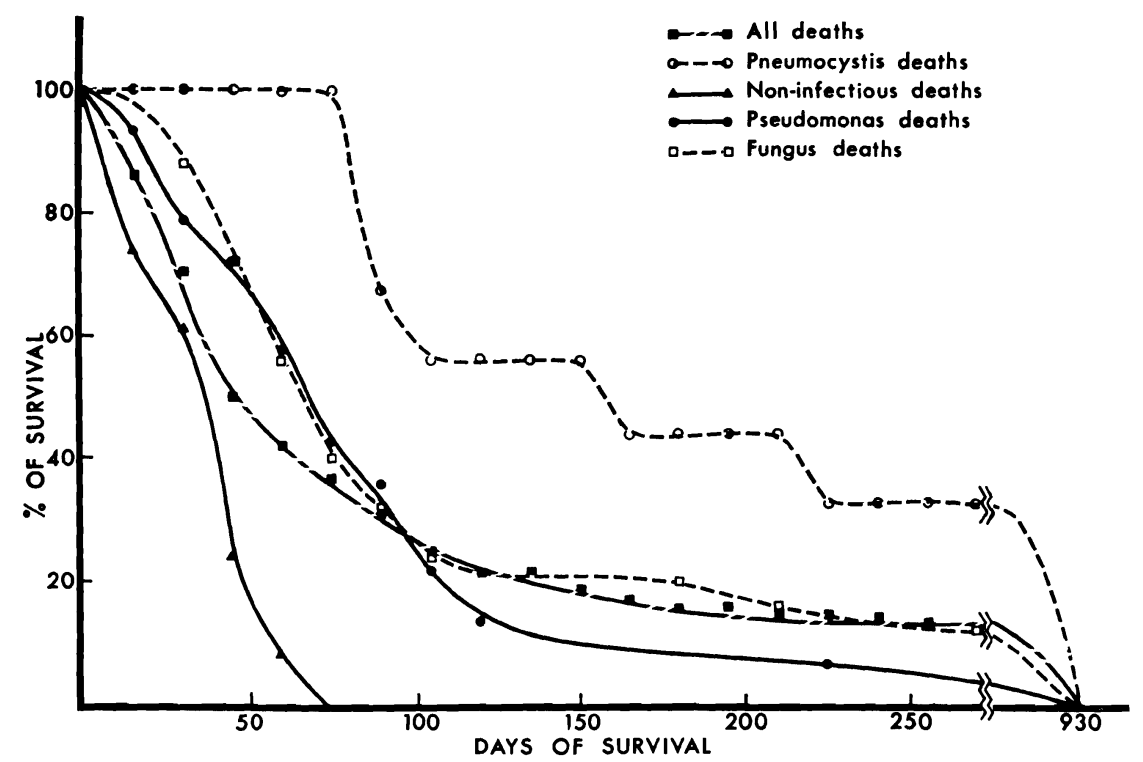

FIG. 1. Per cent survival with time among fatalities, according to cause of death. Noninfectious deaths are virtually nonexistent after fifty days; rate of death from fungus and pseudomonas closely approximates the overall death rate, but deaths with pneumocystis infection occur appreciably later.

or pneumocystis infection shows clearly that noninfectious death is an early event, fungi and pseudomonas cause death at a rate which approximates that of the over-all death rate, and, significantly, pneumocystis becomes an important factor only at an appreciably later time (Fig. 1).

The anatomic characteristics of the infections were those which might be expected in patients with poor defense mechanisms and, in many cases, depressed bone marrow function [11]. Frequently, the growth of organisms and their necrotizing effects seemed virtually unopposed by the host. Large foci of necrosis with abscesses, little evidence of granulation tissue response, massive fungus proliferation, widespread "selective vasculitis" [12] and poor or absent polymorphonuclear response were the rule. Although the infections were most commonly pulmonary, peritonitis, pyelonephritis with abscesses, meningitis and encephalitis were also encountered. Specific effects of toxic antibiotics were not recognized.

One patient, mentioned previously [11], died of hemorrhagic pancreatitis without evidence of infection other than cytomegalovirus eighty-three days after receiving a transplant. Another patient who died 665 days after transplantation had severe pancreatitis in addition to multiple infections including aspergillosis, pneumocystis pneumonia, cytomegalovirus infection and an unidentified sporozoon in the liver, peripancreatic fat and heart. Many other patients were found to have varying degrees of nonhemorrhagic pancreatitis at autopsy. Although occasional small fat emboli were observed in some cases, this was not found to be the cause of death in any case, and in every instance the emboli were so minor as to be considered insignificant. Fat embolism has been reported to be a cause of death in transplant recipients [13]. Small pulmonary thromboemboli were common, but appeared to be associated almost exclusively with early death.

Renal failure was only rarely considered to be the prime cause of death. This statement does not ignore the fact that an appreciable percentage of those who died had poor renal function prior to or at the time of death. Since, in the absence of significant infections or other lethal complications, these episodes are frequently successfully managed by adjustment of drug dosage, radiation, dialysis or retransplantation, poor renal function alone seldom was considered to have caused death. It must be pointed out, in addition, that the majority of patients had good renal function at the time of death, with normal or near-normal blood urea nitrogen 
and other function tests, and histologic study of the transplanted kidneys in these cases revealed relatively normal histological findings except in those who had survived for a long time in whom obliterative vascular changes often were apparent [14,15].

As homotransplantation of whole organs moves out of the era of tentative and somewhat heroic experimentation, as understanding of the scientific basis of graft rejection accumulates, and as day-to-day experience with transplant technic is gathered, it becomes possible to analyze the causes of failure with a view toward correcting them. The two outstanding facts that emerge from this study are (1) death in the first three weeks after surgery has become a relatively rare event, and (2) later death is nearly always due to infection which, at present, eludes effective therapy, and the cause of which is to be found early in the patient's course.

In the first sixty-two patients given transplants at these institutions nearly 20 per cent died in the first twenty-four days, with such contributory causes of death as pulmonary embolus, nonfunctioning graft and electrolyte imbalance (Table II). The deaths included four patients who received liver transplants and two with kidneys transplanted from simian donors. With increased understanding of immediate postoperative complications, and with more selective choices of donors and recipients, the early mortality was reduced in the next sixty-one patients to only two patients: one suffered a myocardial infarct, the other died of Pseudomonas septicemia. Thus it seems clear that technical problems related to the surgery itself as well as complications arising during the early postoperative period have been minimized.

On the other hand, late infection remains an unconquered problem. Seventy-eight per cent of late deaths in the first series of patients, and 88 per cent in the second series resulted from intractable infection. It appears most likely that the immediate cause is the damage to host defense mechanisms which must be inflicted to achieve graft tolerance. The events leading ruthlessly to this damage occur within the first weeks after surgery; those patients whose early need for prednisone and immunosuppression is high and remains high are the ones who will subsequently succumb to infection.

It now seems generally agreed that therapy with antimetabolites and adrenal corticoids in large doses alters the patient's metabolism, thus rendering him more vulnerable to infection [4,11]. Infection may be due to organisms which are ordinarily pathogenic, ubiquitous nonpathogens, saprophytes or potentially pathogenic organisms commonly present in subinfecting quantities. To a considerable extent the mechanisms involved in antimicrobial defense are depressed pari passu with those involved in foreign organ graft rejection; depression of one will therefore adversely affect the other. Some patients are unable to tolerate their grafts as well as others and therefore require more therapy; thus, they suffer more severe damage to their defense mechanisms. These patients are ultimately unable to withstand the onslaught of microbial infestation. If infections with ordinary pathogens are arrested in these patients with antibiotics therapy, pseudomonas or fungus infections develop. If they avoid these organisms, they eventually fall prey to pneumocystis (Fig. 1). The change in therapy since October 1964 has not significantly altered this late mortality due to infection despite the use of smaller doses of azathioprine. In fact, analysis of the course of many patients appears to incriminate prednisone specifically as the most important causative factor in the development of infection. Patients who require continuous large doses of prednisone to forestall rejection or who, faced with a late rejection, suddenly require a greatly increased dose are the ones who die of infection [16]. It must be concluded that progress in therapy with nonspecific immunosuppression-using drugs of general toxicity to immune mechanisms - has reached an impasse. Further progress in reducing mortality must depend on other avenues.

Is there a way out of this dilemma? Final success presumably awaits more complete elucidation of the nature of histocompatibility antigens, the corresponding genetic apparatus which determines these antigens and the development of rapid screening tests for them [17]. In the meantime, it can be hoped that efforts now under way to provide a closer match of donor and recipient tissue antigens, or to provide more specific immunosuppression, will result in the need for less intense general immunosuppressive measures and less liability to infection [18j. One can attempt closer and closer antigen match of donor and recipient in the hope of avoiding offending antigens in the graft. Measures aimed specifically at suppressing graft rejection with minimal

VOL.42, MARG H 1967 
effect on general protective mechanisms include the administration of antilymphocyte serum, extracorporeal lymphocyte radiation and thoracic duct dialysis.

Antihuman lymphocyte globulin has been given a clinical trial as an adjuvant agent at these institutions in the period since the study reported herein was terminated. Antihuman lymphocyte globulin was prepared for intramuscular injection from the serum of immunized horses. From June to December 1966 it was used in the treatment of twenty patients after renal transplantation, in accordance with guidelines derived from previous animal experiments. The antihuman lymphocyte globulin was added to therapy with azathioprine and prednisone, and its use restricted to the critical first four postoperative months.

Nineteen of the patients are well; the only death resulted from a technical accident. Severe rejection has not been observed. The doses of azathioprine and prednisone used have been less than in any previous series of transplantations at our institutions. There has been only one serious infectious complication in the series. Renal function in all ten of the patients who received a transplant more than three months ago is normal.

The question of foreign protein toxicity was examined in these patients in collaboration with Drs. K. A. Porter, B. Seegal and G. Andres of London, New York and Rome, respectively. Delayed but definite increases in precipitin and antisheep red cell titers were regularly seen. Relatively minor anaphyllactoid reactions occurred in three patients, which did not necessitate therapy in two. Homograft biopsy specimens obtained after 108 to 145 days in the first eight cases were examined with conventional as well as labeled antibody technics. There was no equine protein in any of these eight homografts, nor was there other evidence of "foreign protein nephritis."

Developments such as these may lead to improvement in the rate of infection, but in the meanwhile exhaustive efforts to diagnose infection promptly must be made, and the clinician must maintain extraordinary alertness, especially when treating patients who require large doses of drugs. Organisms commonly considered nonpathogenic must be suspect. Cultures must be kept long enough to grow fungi, and tracheal aspirates should be stained routinely with methenamine silver for demonstration of fungi as well as pneumocystis. In many cases lung biopsy should be considered. During periods of particular danger, i.e., when drugs are needed in large doses, patients should be carefully shielded from environmental contaminants. In other series, staphylococci and other common pathogens have been frequently associated with death [19-21]. The fact that only a few patients in this series succumbed to infection by common pathogens may perhaps be due to maintenance of an extraordinary degree of alertness, as these organisms were identified quite commonly $[22,23]$ but the patients were treated vigorously and early. Although the full spectrum of the mixed infections was unrecognized in some cases, the site of infection and the causative organism were known prior to death in most cases. Nevertheless, therapy was ineffectual in the fatalities reported herein.

Pancreatitis has been encountered not uncommonly in patients receiving transplants, and two patients with hemorrhagic pancreatitis at death are included in this series. Many others had varying degrees of mild pancreatitis. This has been reported previously from this institution [11,24] and elsewhere [25]. Whether this was related to pretransplant uremia, drug therapy or immunologic damage remains problematical. A study of this problem is in preparation.

Viral infections, although commonly diagnosed, were probably present but undiagnosed in many other cases. One of the most interesting presumed viral diseases was hepatitis, which occurred in several patients but was the cause of death in only one patient examined at autopsy at this center. In a second patient less severe acute hepatitis, demonstrated by serial biopsies, persisted for over six months. A third patient died elsewhere, reportedly of hepatitis. Whether this is infectious or posttransfusion hepatitis, intensified or prolonged by drug therapy, or whether it is drug-induced hepatitis, remains speculative. Azathioprine is hepatotoxic to dogs [26] but histologic analysis of the liver in patients who died after treatment with this drug has not supported the idea that it is hepatotoxic in man [27].

Herpes zoster occurred in eight patients, and was present at death in one; in each case it pursued a clinical course which was not unusual, and was accompanied by a prompt rise in antibody titer [28].

The most common viral infection was due to 
cytomegalovirus, diagnosed by its characteristic morphology, cultural studies and antibody titers $[8,11]$. Rarely was this organism thought to be related to a specific lesion, and in no case did it appear to be the primary cause of death. A recent report suggests that cytomegalovirus may occasionally cause death in transplanted patients [29]. This opinion was based on the presence of hyaline membranes and interstitial pneumonia. However, we have seen many cases with septal cell hyperplasia, small lymphoid nodules, occasional hyaline membranes, interstitial edema and fibrosis, all of which are commonly found in the lungs during infections with a variety of viruses, even in lungs which were apparently devoid of cytomegalovirus or other identified viral agent. It is difficult to assign a direct cause-effect relationship of a specific virus to these abnormalities but we have assumed that the changes indicate an undiagnosed viral infection. Drug effects and immunologic injury clearly cannot be ruled out.

We conclude from this analysis of the causes of death in 123 consecutive patients who received transplants that postoperative mortality has become almost negligible. However, this has focused attention all the more on the delicate problem facing the therapist: the measures which suppress immunologic rejection of the transplanted organ also affect adversely the defense mechanisms against infection. By far the most important cause of death in this series, accounting for more than 80 per cent of fatalities, was infection with unusual organisms not susceptible to conventional antibiotic therapy, occurring in patients whose need for large doses of steroids and immunosuppressive drugs dates to the early postoperative period. Recent efforts at reducing the need for immunosuppressive therapy, using antilymphocyte globulin, and other efforts to minimize immunologic differences between donor and host, may lead to considerable amelioration of this extremely vexing problem.

Rolla B. Hill, JR., M.D. Bruce E. Dahrling, iI, M.D. Thomas E. Starzl, M.D., PH.D. AND David Rifkind, M.D., PH.D. Departments of Pathology, Surgery and Medicine University of Colorado Medical Center Denver, Colorado 80220

\section{RefERENGES}

1. Merrill, J. P., Murray, J. E., Harrison, J. H. and GuILD, W. R. Successful homotransplantation of human kidney between identical twins. J.A.M.A., 160: 277, 1956.

2. Schwartz, R. and Dameshek, W. Drug-induced immunological tolerance. Nature, 183: 1682, 1959.

3. Starzl, T. E. Experience in Renal Transplantation. Philadelphia, 1964. W. B. Saunders Co.

4. Russell, P. S. and Monaco, A. P. The biology of tissue transplantation. New England J. Med., 271: 776, 1964.

5. Starzl, T. E., Marchioro, T. L., Terasaki, P. I., Porter, K. A., Faris, T. D., Herrmann, T. J., Vredevoe, D. L., Hutt, M. P., Ogden, D. A. and Waddell, W. R. Chronic survival after human renal homotransplantation: lymphocyteantigen matching, pathology, and influence of thymectomy. Ann. Surg., 162: 749, 1965.

6. Starzl, T. E. Experience in Renal Transplantation, pp. 11 and 68. Philadelphia, 1964. W. B. Saunders Co.

7. Terasaki, P. I., Porter, K. A., Marghioro, T. L., Mickey, M. R., VRedevoe, D. L., Faris, T. D. and Starzl, T. E. Serotyping for homotransplantation. viI. Selection of donor kidneys for 32 recipients. Ann. N. Y. Acad. Sc., in press.

8. RIFKIND, D. Cytomegalovirus infection after renal transplantation. Arch. Int. Med., 116: 554, 1965.

9. Rifkind, D., FARIs, T. D. and Hill, R. B., JR. Pneumocystis carinii pneumonia. Studies on the diagnosis and treatment. Ann. Int. Med., 65: 943, 1966.

10. Rifkind, D., Marghioro, T. L., Schneck, S. A. and Hill, R. B., JR. Systemic fungal infections complicating renal transplantation and immunosuppressive therapy. Am. J. Med., in press.

11. Hill, R. B., JR., Rowlands, D. T. and Rifkind, D. Infectious pulmonary disease in patients receiving immunosuppressive therapy for organ transplantation. New England J. Med., 271: 1021, 1964.

12. Teplitz, C. Pathogenesis of Pseudomonas vasculitis and septic lesions. Arch. Path., 80: 297, 1965.

13. Jones, J. P., Engleman, E. P. and Najarian, J. S. Systemic fat embolism after renal homotransplantation and treatment with corticosteroids. New England J. Med., 273: 1453, 1965.

14. Porter, K. A., Owen, K., Mowbray, J. F., Thompson, W. D., Kenyon, J. R. and Peart, W. S. Obliterative vascular changes in four human kidney homotransplants. Brit. M. J., 2: 639, 1963.

15. Porter, K. A., Marchioro, T. L. and Starzl, T. E. Pathologic changes in 37 human renal homotransplants treated with immunosuppressive drugs. Brit. J. Urol., 37: 250, 1965.

16. Starzl, T. E., Marchioro, T. L. and Iwasaki, Y. Attributes of clinically used immunosuppressive drugs: The possible future value of antilymphoid sera. Fed. Proc., in press.

17. Billingham, R. E. Tissue transplantation. Scope and prospect. Science, 153: 266, 1966.

18. See various papers in Proceedings of the Seventh International Transplantation Conference. Ann. N. Y. Acad. Sc., in press.

19. Dempster, W. J., Harrison, C. V. and Shackman, R. Rejection process in human homotransplanted kidneys. Brit. M. J., 2: 969, 1964.

20. Goldman, R., Goodwin, W. E., Kaufman, J. J.,

VOL. 42 , MARGH 1967 


\section{Editorial}

Martin, D. C., Glasscock, R. J. and Nourok, D. S. Sixteen cases of renal homotransplantation. Arch. Int. Med., 114: 601, 1964.

21. Hamburger, J., Vaysse, J., Grosnier, J., Auvert, J., Lalanne, G. M. and Hopper, J. Renal homotransplantation in man after radiation of the recipient. Am. J. Med., 32: 854, 1962.

22. Rifkind, D., Marchioro, T. L., Waddell, W. R. and StarzL, T. E. Infectious diseases associated with renal homotransplantation. I. Incidence, types and predisposing factors. J.A.M.A., 189: 397, 1964.

23. Rifkind, D., Marchioro, T. L., Waddell, W. R. and Starzl, T. E. Infectious diseases associated with renal homotransplantation. Ir. Differential diagnosis and management. J.A.M.A., 189: 402, 1964.

24. Starzl, T. E., Marchioro, T. L., Holmes, J. H., Rifkind, D. and WAdDell, W. R. Factors in successful renal transplantation. Surgery, 56:296, 1964.
25. Tilney, N. L., Collins, J. J., JR. and Wilson, R. E. Hemorrhagic pancreatitis. Complication of transplantation. New England J. Med., 274: 1051, 1966.

26. Starzl, T. E., Marchioro, T. L., Porter, K. A., TAYlor, P. D., Faris, T. D., Herrmann, T. J., Hlad, C. J. and Waddell, W. R. Factors determining short- and long-term survival after orthotopic liver homotransplantation in the dog. Surgery, 58: 131, 1965.

27. Hill, R. B., JR., Porter, K. A. and Massion, G. G. Hepatic reaction to renal transplants modified by immunosuppressive therapy. Iron accumulation in hepatic injury. Arch. Path., 81: 71, 1966.

28. RifKIND, D. The activation of varicella-zoster virus infections by immunosuppressive therapy. J. Lab. EO Clin. Med., 68: 463, 1966.

29. Kanich, R. E. and CRaighead, J. E. Cytomegalovirus infection and cytomegalic inclusion disease in renal homotransplant recipients. Am. J. Med., 40: 874, 1966. 